\title{
Bloom syndrome
}

INSERM

\section{Source}

INSERM. (1999). Orphanet: an online rare disease and orphan drug data base. Bloom syndrome. ORPHA:125

Bloom syndrome (BSyn) is a rare chromosomal breakage syndrome characterized by a marked genetic instability associated with pre- and postnatal growth retardation, facial sun-sensitive telangiectatic erythema, increased susceptibility to infections, and predisposition to cancer. 